\title{
Factors of formation of foreign language communicative competence of future construction specialists through overcoming the language barrier
}

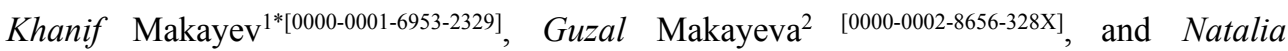 \\ Sigacheva1 [0000-0002-8746-6828] \\ ${ }^{1}$ Kazan (Volga Region) Federal University, Institute of International Relations, Russia \\ ${ }^{2}$ Kazan State University of Architecture and Engineering, 420043, Zelenaya st., Kazan, Russia
}

\begin{abstract}
Employees at construction sites need to have good communicative competence on all the issues occurring there. The survey of higher school students revealed presence of language barriers in the process of communication. They should be able to cope with all the speech situations requiring proper practical language skills. Therefore, the research considers necessity of development of communicative speech skills of future construction specialists in English considering the factors that would contribute to overcoming language barriers. To realize this, the authors empirically surveyed groups of a higher school final-year students to improve their language level through mastering their communicative skills on the base of necessary teaching factors, and simultaneously eliminating possible obstacles. The research was conducted on the base of communicative method and the teaching-practicing-controlling approach supported by observing, questioning, and surveying methods. The results obtained show that proper practical development of future specialists' communicative skills taking into account all kinds of barriers can improve their professional language growth and overcoming their speech barriers. The research results obtained one can use in language teaching practice, as well as for making some possible contribution to education and through it communication skills of research participants' speech development.
\end{abstract}

Key words: communication, skill, construction, student, language, barrier, competence.

\section{Introduction}

Competent use of the professional English language by just graduated young specialists at construction sites means understanding any speech adequately and using the information got from interlocutors' messages in the professional fields more effectively. While solving the problem one can face great obstacles like so-called language barrier that very often leads to impossibility to realize a communicative task. Although there are many teaching

\footnotetext{
*Corresponding author: makaev-63@mail.ru
} 
methods, graduates of universities, especially of non-linguistic ones, have great difficulties in production of even low-level foreign language speech. This indicates that the level of formation of this competence at higher schools not satisfactory in the meantime. Analysis of corresponding publications, conversations with students, as well as young specialists confirm that they have difficulties in oral interviews, when performing tests designed to diagnose the level of proficiency in both general English and the language for special purposes. The difficulties are explained in different ways. The first reason, perhaps the most important one, may be a strong fear to produce a speech. Someone cannot remember the necessary words for greeting and starting a conversation, while others experience «run away» thoughts, which baffles them, and so on. All these facts confirm the presence of the so-called language barrier, which prevents effective foreign language communication between representatives of multilingual specialists, as well as the ones of construction field in particular. Therefore, the key purpose of the research is to deal with the problem of overcoming the language barrier for vocationally oriented foreign language teaching due to appropriate teaching factors, ways and techniques. The topicality of overcoming the language barrier are underlined by such scientists as $[1,2,3,4,5,6]$. The research was based on the method of observing, questioning, and surveying and the communicative method. The research confirms the most effective factors to be, namely, a competent teacher, increasing the motivation, consideration of the ratio of speech and language, and consideration of communicative speech abilities of students is vital in solving the problem. Findings of this study prove that all teaching approaches, methods, ways, and techniques are effective if used together. Considered are different definitions of language barrier and all kinds of barrier, that is, psychological, linguistic, communicative, and social cultural barrier. Motivation for mastering the professional language is achieved due to vocationally oriented teaching material. The research shows that vocationally oriented foreign language teaching is much better to put into practice through overcoming the language barrier. The research stated that students' professional language growth and overcoming their speech barriers was enabled by the use of necessary factors which can contribute to forming their communicative competence. The results improve language teaching practice, make some contribution to education proper practical development of future specialists' communicative skills taking into account all kinds of barriers can improve their professional language growth and overcoming their speech barriers. The results can be used in language teaching practice, as well as for making some possible contribution to education and to research participants' speech development.

\section{Materials and methods}

The research's issue was considered by such foreign scientists as $[7,8,9,10,11]$ and others, as well as Russian scientists [12, 13, 14, 15, 16, 17] and others. Great contribution to realizing the research was made by the materials of survey of higher school students. The aim of the survey was to reveal any presence of language barriers in the process of communication. The main methods were the method of observing, questioning, and surveying, the communicative method. The method of observing, questioning, and surveying learned the original communicative skills level of the research participants, the communicative method being the main one in overcoming the language barrier in considering of all the factors taken into account in the research. 


\section{Results}

The factors considered in the research for the implementation of the system for overcoming the language barrier during formation of foreign language communicative competence are: - increasing motivation for confident spontaneous production of foreign language speech; - guiding, supporting and controlling the role of the teacher as an example of exemplary foreign language speech for students;

- taking into account the ratio of speech and language in the process of foreign language training;

- taking into account the communicative speech abilities of students for foreign language training;

\subsection{Motivation for confident spontaneous production of foreign language speech}

The main condition for overcoming the language barrier, in our opinion, is motivation, since in any kind of activity, if a person wants something very strongly, then he will certainly achieve certain success in this. Conversely, the lack of motivation to do something does not bring a positive result. I.A. Zimnyaya by motivation means «the totality of the most varied motivators, needs, motives, feelings, rules, norms, desires, etc.» [3]. In psychology, motivation is understood as «the process of intervention or the internal state of the organism, prompting or leading it to action» [18, p.464].

It is well known that «motivation is an invariably strong guarantor of successful language learning» [19, p. 123-163]. When teaching a language, in order to succeed, we must provide students with good speech motivation for communication, because, according to Arnold, «communication between people in the classroom brings success more efficiently and faster than any teaching material and technology» [20].

In the scientific, methodological and psychological literature there are defined internal and external motivation. Intrinsic motivation is a student's personal desire to study a particular discipline, a conscious decision-making, recognition of the importance of this decision in his life.

This motivation is more correlated with the emotional side of a person studying a foreign language. Internal motivation arouses interest in performing an activity, in our case, in the formation of foreign language communicative competence, and in the forms, methods and ways of its effective implementation. The internal motive is aimed at achieving personal plans. It comes from within a person, for example, to become a successful specialist, to go abroad for a high-paying job, etc. and stimulates the internal reserves of the personality for educational and cognitive motives of learning.

External motivation is the objective prerequisites for studying the discipline. It is characterized by a pragmatic orientation of language learning, when the student is guided by the principle of usefulness - the uselessness of acquired knowledge and skills for himself. An external motive for learning a foreign language explains the need, for example, to pass an exam in order to obtain a diploma, scholarship, etc. Therefore, it does not adequately take into account the need to obtain knowledge and skills.

The achievement of the research's aim depends on the right correlation of internal and external motivation. For this, we learned the students' personal requirements for foreign language training, its awareness and effectiveness, their current knowledge and skills on English. It is important to use the desire of the student to get approval that reflects a psychological need. It is known that a person always lacks this, therefore, he is motivated to do something that is aimed at satisfying this need.

When doing the experimental exercises, we considered such factors as: 
1) the aim of mastering the language (for communicating with foreign colleagues, during studying abroad, for professional purposes);

2) effectiveness (the student's ability to track the achievement of clear tangible results);

3) communication (activation of cognitive and intellectual interaction between students and teachers through discussion of problems and joint activities);

4) game activities (modeling situations in the professional sphere);

5) vocational guidance (integration of the subject «Foreign language» into the system of training a specialist and the student's awareness of its functional significance) [21, p. 106].

During the research our attention was paid to the fact that successful learning presupposes an effective correlation between learner, learning material, teacher, and context. So, in order to motivate language learners, we capitalized on learners' personalities by using learning material and methods that suit their interests and needs, with a contextual approach leading in educational process. Research participants were informed about the essence of their future specialty, since most of them usually have no idea about this. Educational material comprised real situations that require communication. The motivating power of the teaching material was to be so powerful as to make students think about what they are talking about, but not about grammatical correctness, since the acquisition of a language cannot be realized by automatic memorization of the rules of grammar. Such approach enabled the students to reach definite level of spontaneous speech. It presupposed the presence of a language environment, overcoming the language barrier and providing motivation.

\subsection{Guiding, supporting and controlling role of the teacher as a model of foreign language speech}

In creating a strong and deep motivation of students for foreign language training, the role of a teacher is great. He/she must have much knowledge in pedagogics, he/she must have good professionalism and a high level of professional and general culture, the presence of positive qualities, professional competence. He/she must be competent in students' profession too. The teacher must master the taught discipline at a high level, must know what the language is, its culture, know how it functions, what the ratio of language and speech is, the ratio of all four types of speech activity.

The main qualities of a teacher should be patience, warmth, flexibility, openness, sensitivity, as well as self-confidence. The teacher must show enthusiasm, support the inspiration and confidence of students, their positive attitude towards the foreign language being studied. This is supposed to eliminate any kind of barriers during learning process.

The teacher should not only know and be able to all of the above, «the main role here is played by his ability to transfer this knowledge, skills and abilities to his students» [22].

An important aspect of the teacher's activity is his psychological and linguodidactic knowledge and skills, the use of which would help to overcome the language barrier in the process of forming the foreign language communicative competence of students - future specialists.

It is important for a teacher to be ready methodologically, psychologically and technologically to use various technologies to accomplish the task of forming a foreign language communicative competence. This requires a highly innovative qualification of a teacher, the ability to conduct an implementation experiment, diagnose changes, choose the right book and pedagogical technology.

Russian and foreign high school experts consider the high school teacher to have good knowledge, skills and abilities both in his/her subject and in the field of their students' profession [23, p.98]. 
Professionals understand that proficiency in a foreign language is an important factor for their competitiveness in the labor market. Professionals who know the language are in great demand in companies for which foreign language skills of employees become part of their intellectual capital [24]. Companies with employees with foreign language skills are economically competitive and therefore encourage their employees to learn foreign languages. This should be a strong motivation for students - future specialists to learn a foreign language.

It should be noted that, unlike other activities, learning a foreign language takes too much time and effort. To master it, constant and systematic studies are needed, many people are not ready for this, enormous volitional efforts are needed, which they did not even know about before. All of the above facts require an increase in the motivation of people studying a foreign language for their foreign language training in order to effectively overcome the emerging barriers to language acquisition.

\subsection{The ratio of speech and language in the process of foreign language training}

Speech and language are a single phenomenon of the human language. If a language is a set of means of communication between people through the exchange of thoughts, and the set of rules for the use of these means is manifested in speech, then speech uses these available linguistic means and rules in the very linguistic communication of people. Speech means the functioning of language.

One of the main features of the relationship between speech and language is that language acts as a means of communication. Speech practically realizes this communication, performing a communicative function, i.e. it is the embodiment and implementation of the language. According to our research, overcoming the language barrier for the formation of foreign language communicative competence involves learning the language precisely through the practical implementation of communication, without putting forward the need to learn the language as a system in the first place.

Another feature of the relationship between language and speech is that if language is formal and abstract, then speech is its material manifestation, consisting of sounds perceived by the ear. Speech may be unspoken, i.e. implicit, and language is always explicit. Here it is necessary to introduce the term «inner speech», developed by L.S. Vygotsky, who said that «inner speech is nevertheless speech, that is, a thought associated with a word» [25, p. 290].

Unlike language, speech is more variable, it reflects a person's experience, and language reflects the «picture of the world» of people speaking it. Speech depends on the situation and context, since it is active and dynamic, in which language units acquire situational meanings that are absent in the language. The language does not depend on the environment of communication, it is stable, static. Therefore, in foreign language training, it is important to accustom students to the idea that the same word or expression can acquire different meanings in different situations of communication. The task of a person speaking a foreign language is to correctly use the required linguistic unit in the corresponding speech situation of communication.

Before the advent of the communicative method, teaching a foreign language went from language to speech. This meant that the process of language learning began with an analysis of the theoretical system of the language. The sentences were made only for demonstration and consolidation of grammatical and lexical material. Moreover, the content of these proposals could not be called communicative. As a result, people studying the language knew it well, but could not speak it. This is due to the fact that the language in the classroom was separated from real communication situations. 
In contrast to this tradition, the method «from speech to language» involves the expression of meaning and thought in the first place. The communicative motivation of the student, the speech act itself, is important here. The linguistic aspect of the language fades into the background. Language ceases to be an end in itself, it becomes a means of receiving and transmitting information. If a language is taught precisely as a means of speech realization, its communicative function, which is the main one, is much better visible [24].

So, to develop communicative skills of research participants we organized communication oriented educational process for developing speech skills. In the process of forming and improving speech skills, students learned not the elements of the language system, but developed the skills and abilities of foreign language speech communication. Achieving this goal became possible as the process of foreign language training was as close as possible to the process of speech communication, i.e. modeling communication in communicating.

\subsection{Consideration communicative speech abilities}

By the abilities in learning a foreign language we mean linguistic knowledge and speech skills in all four types of speech activity: speaking, reading, listening and writing. Psychological science, denying, on the one hand, the relationship of abilities with knowledge and skills, on the other hand, recognizes their unity. The manifestation of abilities is associated with the implementation of activities, and activities, in turn, cannot be carried out without abilities. Thus, abilities and any activity are closely interconnected. The process of foreign language training undoubtedly proves that language learners have abilities that are associated with interest and motivation. An increase in interest and motivation directly depends on the degree of success: the better the results of teaching a foreign language are, the more captivating the process of studying the discipline is, as the student learns more new things, begins to feel more practical benefits from knowledge and skills. «The opportunity to achieve success inspires students for further work, increases their motivation for foreign language, professional training, since the skills of teamwork, the ability to understand comrades and help them will be useful in future professional activities» [21, p. 134].

The data of surveys, questionnaires and conversations with students confirmed that, basically, students study a foreign language in order to learn how to communicate in it. Awareness by students of the acquired skills and abilities of foreign language speech communication as a result of educational activities is a strong incentive for the formation of motivation to further improve their abilities. This suggests that the ability for foreign language training, as well as for other types of activity, is interconnected with both interest and motivation. The more the student achieves success in the educational process, the more his desire is to further improve his knowledge and skills.

It is not enough to have abilities; they need to be improved. Systematic and constant practice is a guarantee of success both from a psychological and methodological point of view. But for this it is necessary to choose the correct methodology, the teacher's work must also be at a high level, so as not to extinguish students' interest in foreign language training, not to lower their motivation to master a foreign language.

\section{Discussions}

The factors mentioned in Results section taken only together contribute to eliminating their language barrier if they are used on the base of every student's real level of development as they are interconnected, and exclusion of at least one of them may break down the 
achievement of the required aims of the research. The tasks of the research cannot be fulfilled if the teaching process is realized only considering the linguodidactic principles. Positive results could be achieved by considering the psychological aspect, which would be taken into account equally intensively in close connection with the linguodidactic aspects. Scientists state that such an approach will provide a comprehensive coverage of the problem of the formation of foreign language communicative competence and will contribute to an increase in the level of language proficiency.

According to psychological science, an utterance as an action is composed of microoperations and macro-operations, while the microoperations that make up the utterance (selection, comparison, etc.) are the same for speech in any language. Macrooperations (syntactic forecasting, transformation, etc.) need to be taught specifically, since they depend on the structure of the language and the ways of mastering it. To communicate in a foreign language, it is necessary to master speech actions in this language, that is, master macro-operations in it.

\section{Conclusions}

The consideration of the above-mentioned factors is effective if the tasks for their realization are selected on the basis of the principles of problematic approach, unpredictability, unexpectedness, spontaneity of speech, contextual and situational learning, aimed at generating ideas.

The main directions of overcoming language barriers in the process of forming foreign language communicative competence of structural students are establishing the presence and reasons for the appearance of a barrier, determining their correlation with psychological and linguodidactic difficulties, competent selection of an active productive grammatical and lexical minimum, use of all types of memory: visual, auditory, motor, logical, creating situations of success, interactive forms of foreign language teaching without reliance on the native language, professional orientation of the acquired knowledge, a differentiated approach to trainees.

Required are further researches related to development of communicative skills of students through elimination of the language barrier in the fields of vocationally oriented teaching material, creating an imaginary language environment.

\section{Acknowledgements}

The work is performed according to the Russian Government Program of Competitive Growth of Kazan Federal University.

\section{References}

1. V. L. Bernstein. Ways of forming cross culture communicative competence, «Teaching foreign languages and culture: problems, searches, decisions», Pyatigorsk. International symposium (2005).

2. A. A. Verbitsky, V. F. Tenitscheva. Foreign language speech activity of an engineer, Higher education in Russia, 3, 70-77 (1994).

3. Kh. M. Makayev, S. S. Takhtarova, M. K. Gulkanyan, I. I. Kuznetsova, T. S. Kazymova, The urgency of considering false friends of a translator for construction specialists, IOP Conference Series: Materials Science and Engineering, 890(1), 012205 (2020) DOI: 10.1088/1757-899X/890/1/012205 
4. Kh. F. Makayev, Removing Language Barrier as a Guarantee of Forming Language Competence of a Future Specialist, Scientific theoretical journal. Scientific notes of the University after P.F. Lesgaft, 11, 81 (2011).

5. G. S. Trofimova, Didactic base of forming communicative competence of students, Doctoral Dissertation, (2000).

6. Marium Jamila, Lack of Confidence - A Psychological Factor Affecting Spoken English of University Level Adult Learners in Bangladesh, Department of Languages, Bangladesh Agricultural University, Mymensingh, 2202 (2014).

7. H. J. Bawer. Competence of Foreign Language Teachers in the Area of Vocationally Oriented Language Learning, Language Learning for European Citizenship: Report on Workshop 3A. Schotten (1991).

8. A. Strevens The development of specialist materials for VOLL, Language Learning for European Citizenship: Report on Workshop 3A. Schotten (1991).

9. Özlem Çelik, Orhan Kocaman, Barriers Experienced by Middle School Students in the Process of Learning English, International Journal of Psychology and Educational Studies, Turkey, 3(1), 31-46 (2016)

10. M. Ebata, Motivation Factors in Language Learning, The Internet TESL Journal, XIV. Retrieved, (2013) http://iteslj.org/Articles/Ebata-MotivationFactors.html (reference date 20.04.2021)

11.Z. Dörnyei, Motivational Strategies in the Language Classroom (Cambridge: Cambridge University Press, 2001)

12. I. V. Firsova, Language barrier by a language teaching, The humanities, 1, 9 (2013)

13. E. G. Dadayan, Communication barrier and some reasons for its origin, in Materials of the International Scientific and Methodological Symposium «Teaching Foreign Languages and Cultures: Problems, Searches, Solutions», Lempert readings-VII, 19-20 May, 2005, Pyatigorsk, Russia

14. A. A. Kaskevich, On the results of the study of the language barrier among students of a technical university, Bulletin of the Krasnoyarsk State Agrarian University. Krasnoyarsk, 11, 256-259 (2012)

15. N. A. Nikolaenko, Psychological aspect of overcoming the language barrier in teaching oral speech to students of technical specialties, in materials of the International scientific-practical. conf. «Actual questions in scientific work and educational activities: collection of articles», 30 May 2015, Tambov, Russia

16. E. I. Passov, V. P. Kuzovlev, V. B. Tsarkova and others, Foreign language teacher: Mastery and personality (Moscow, Education, 1993)

17. Kh. F. Makayev, A. R. Baranova, Ways of vocabulary enlargements the English sublanguage of Physics, Journal of Research in Applied Linguistics, 10 (Special Issue), 793-801 (2019)

18. A large explanatory psychological dictionary (Vol. 1. Veche, Ast M, 2000)

19. A. M. Masgoret, R. C. Gardner, Attitudes, motivation, and second language learning, A meta-analysis of studies conducted by Gardner and Associates. Language Learning, 53, 123-163 (2003)

20. J. Arnold, Self-Concept and the affective domain in language learning, self-esteem and foreign language learning (Cambridge Scholars Publishing: Cambridge, 2007)

21. Kh. F. Makaye, Profiling of foreign language training of students as a factor in increasing motivation for professional and career growth, Diss. for the degree of Candidate of Pedagogical Sciences, Izhevsk (2005)

22. M. H. Burt, Viewpoints on English as a Second Language (Regent's Publishing Company, New York, 1977) 
23. Kh. F. Makayev, Profiling of foreign language training of students as a factor in increasing motivation for professional and career growth (USPTU Publishing House, Ufa, 2007)

24. O. V. Flerov, Corporate training in English as a way to improve the level of communicative competence of employees of international companies, Modern Education, 2, 116-140 (2015)

25. O. G. Vetrova, Linguistic problems of intercultural English-language communication in the crash-course of overseas cultural immersion, in Materials of the International Scientific and Methodological Symposium «Teaching Foreign Languages and Cultures: Problems, Searches, Solutions», Lempert readings-VII, 19-20 May, 2005, Pyatigorsk, Russia 